\title{
Psychotes Papi Kostick Web-Based Online
}

\author{
Mikael Duhantatya ${ }^{1}$, Erdhi Widyarto Nugroho ${ }^{2}$, \\ Albertus Dwiyoga Widiantoro ${ }^{3}$ \\ ${ }^{1,2,3}$ Departmen of Information System, Soegijapranata Catholic University \\ 1,2,3 Jl. Pawiyatan Luhur Sel. IV No.1, Bendan Duwur, Kota Semarang, Jawa Tengah 50234 \\ 1duhantatya@gmail.com \\ 2erdhi@unika.ac.id \\ 3yoga@unika.ac.id
}

\begin{abstract}
Technological progress has experienced very rapid development. Technology that has developed began to slowly replace the conventional way of becoming more modern, especially in terms of psychological tests. The psychological test known as a psychological test is a test that is carried out to measure aspects of the individual psychologically. One of these psychological tests is the PAPI Kostick Test which is an inventory report of a person's personality in a work environment. The online PAPI Kostick test was developed using HTML, CSS, JavaScript, and PHP. Application testing was conducted to obtain correlation in terms of appearance, comfort, convenience, satisfaction, and long-term use.
\end{abstract}

Keywords- PAPI Kostick, website, psychological test, technology, online

\section{INTRODUCTION}

Technological progress has experienced very rapid development. Technology that has developed began to slowly replace the conventional way of becoming more modern, especially in terms of psychological tests. The psychological test known as a psychological test is a test that is carried out to measure aspects of the individual psychologically. Psychological tests can be considered as written interviews, because they use a large number of questions indirectly, one or more considerations are more free to answer for those who fill / answer them from direct verbal interviews.

Psychological test can provide better information than direct and straightforward questions. Psychological test can take the form of tests that project image, written, and so on to measure the function of one's cognitive and emotional abilities starting from the level of talent, interest, intelligence, to the personality of the person. From the results depicted in the psychological test obtained an overview of the person who will later be used as information that can help the person in several fields, for example: the field of suitable work, talent, specialization, matching study specialization and so on.

Psychological testing is basically a diagnostic effort with certain measuring instruments made by psychologists to provide a picture of the potential possessed by someone or to distinguish a person's behavior from others through giving certain problems [1]. By combining technology and psychological test, it is expected to be able to change the psychological test that used to be done online. Psychological tests conducted online, will make the psychological test process more time-saving and effective.

Psychological testing is still done in a conventional way, of course it requires quite a long time, for psychology PAPI Kostick itself takes 15-45 minutes, then to send the results the fastest 3 days after the test and the maximum takes up to 1 week after the test. By using an online psychological test system, it will reduce the use of paper which is quite large, especially the use of paper for answer sheets and problem sheets. Therefore, the psychological test, especially PAPI Kostick, which was changed from the conventional way to being online based, would have a very large positive impact on the activity. Psychological Tests have a variety of types, one of which is the Personality and Preference 
Inventory (PAPI) Kostick. PAPI Kostick is a personality report (self report inventory), consisting of 90 pairs of short statements related to work situations, which involve 20 aspects of personality that are grouped in 7 fields: work direction, boss-subordinate position (followership), relations social (social nature), work activities (activity), temperament characteristics (temperament), work style (work style), and leadership (leadership) [2].

Therefore the research was carried out while carrying out the making of the websitebased PAPI Kostick online psychotest application to replace the existing one, which was conventional because of the positive impact it produced, including time efficiency, fast data processing, and saving paper consumption.

\section{LITERATUR REVIEW A. PAPI Kostick}

According to Dr. Max Martin Kostick (1960) Inventor of PAPI Kostik and Professor of Industrial Psychology from Massachusetts, USA. PAPI Kostick measures psychodynamics by paying attention to the environment, including behavior and corporate values (values) that are applied in a company / work situation in the form of motives (need) and standards of behavior according to the perception of the candidate (role) recorded during psychotest.

Over time and studies conducted by several psychologists, produced many versions and various but still on the same goal. Some versions were born by experts, among others, the Swedish Version was introduced in the early 1980s and this version was introduced in 1997 with the ipsative (PAPII) and normative (PAPI-N) version. The ipsative version, PAPI-I, was built to be used for personal development. The normative version, PAPI-N, is intended to be used for comparison and selection [3].

With the psychology of PAPI Kostick online with website-based aims to facilitate all processes from the beginning to the end. Psychological applications are built with a user interface display so that prospective employees become more comfortable and not confused when using it [4]. Psikotes Based Work Unit Determination System to be built on other platforms such as android due to high use of gadgets at this time [5]. For now it is still being developed at the website stage.

\section{B. Tes Kepribadian}

Personality is an impulse that regulates a person's behavior or gives directions in a certain direction. This will make someone respond to the problem in a reasonable way according to the situation at hand. Personality can also be interpreted as a way that someone does in responding to a situation or a way of acting that someone likes against a particular situation or person. Personality is usually measured using a self-assessment cake. Kueisioner is a test that directly asks aspects of a person's personality, how to deal with other people, measure the ability to deal with pressure consistently and objectively, and attitudes of a person's behavior in general.

The test is the same as a personality test or personality test [6]. The reasons for choosing web-based psycho test include the application of this web-based personality test that cannot completely replace the energy of a psychologist but can help a group of psychologists to accelerate the scoring stage of test participants so that the time needed will be faster and more effective, this websitebased personality test application can also minimize errors in checking test results caused by human errors [7].

\section{PHP}

PHP is the most widely used script programming language today. PHP is widely used to program dynamic websites, although it is not possible to use it for other uses. Famous examples of PHP applications are forums (phpBB) and MediaWiki (software behind Wikipedia). PHP can also be seen as another option from ASP.NET/C\#/VB.NET Microsoft, Macromedia ColdFusion, JSP / Java Sun Microsystems, and CGI / Perl. Examples of other more complex applications in the form of CMS that are built using PHP 
are Mambo, Joomla!, Postnuke, Xaraya, etc. [8].

Some reasons that are considered using PHP include: easy to learn, capable of cross platform, free, supported by various types of web servers, and supports multiple databases [9].

\section{Website}

Website (Website) is a collection of web pages related to other related files. In a website there is a page known as the home page. The home page is a page that was first seen when someone visited the website. From the home page, the end can click on a hyperlink to move to another page found on the website [10].

\section{E. MYSQL}

MySQL is a SQL database management system (English: database management system) or a multithreaded, multi-user DBMS, with around 6 million installations worldwide. MySQL AB makes MySQL available as free software under the GNU General Public License (GPL), but they also sell under a commercial license for cases where its use does not match the use of GPL. Relational Database Management System (RDBMS).

MySQL is a Relational Database Management System (RDBMS) that is distributed free under the GPL (General Public License). Where everyone is free to use MySQL, but may not be a commercial product. MySQL is actually a derivative of one of the main concepts in the database for a long time, namely SQL (Structured Query Language) [11].

Reasons for choosing MySQL because, MySQL can run stable on various operating systems such as Windows, Linux, FreeBSD, Mac Os X Server, Solaris, Amiga, and many more. The operating system on the LAPAN FTP server uses FreeBSD 6.0. MySQL is distributed in open source [12].

\section{F. JavaScript}

JavaScript is a small, light scripting language, and also focuses on objects that are listed in
HTML code and processed on the client side. Using JavaScript can make a website more interactive by providing additional capabilities to HTML through executing commands on the browser side. JavaScript can respond to user commands quickly and make web pages more responsive [13].

\section{G. CSS}

Cascading Style Sheets (CSS) is one of the languages for managing the appearance of the web that functions to separate between design and content. CSS can be written to redefine HTML tags or by adding the id attributes and classes to HTML tags [14].

\section{RESEARCH METHODOLOGY}

To develop a PAPI psychological test application web-based online Kostick uses the waterfall method. Applications developed using PHP, HTML, and JavaScript programming languages. At the development stage the server uses localhost, namely xampp. For database server providers use MySQL with the SQL language. Websitebased database management is PHPMyAdmin. In building the psychological application PAPI Kostick online, of course there is a workflow that works behind it all. Workflow plays an important role in a system. The flow of the workflow process contains the stages of how the system works from beginning to end. Without a clear and detailed process flow, the system will not run perfectly. Because the accuracy of the following picture is needed.

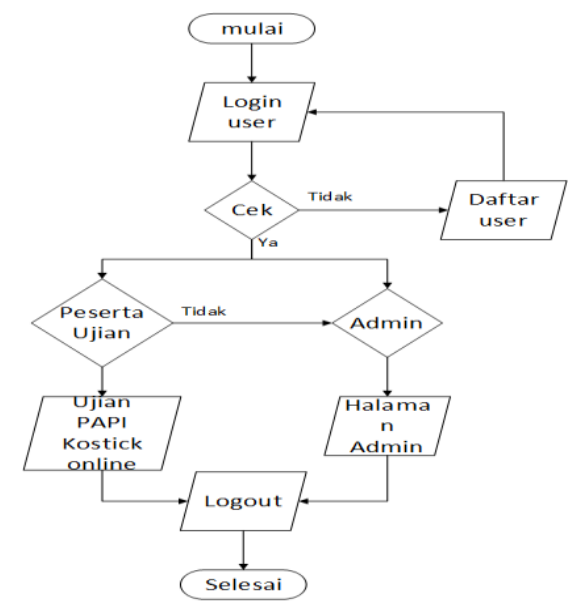

Figure 3.1 Workflow 


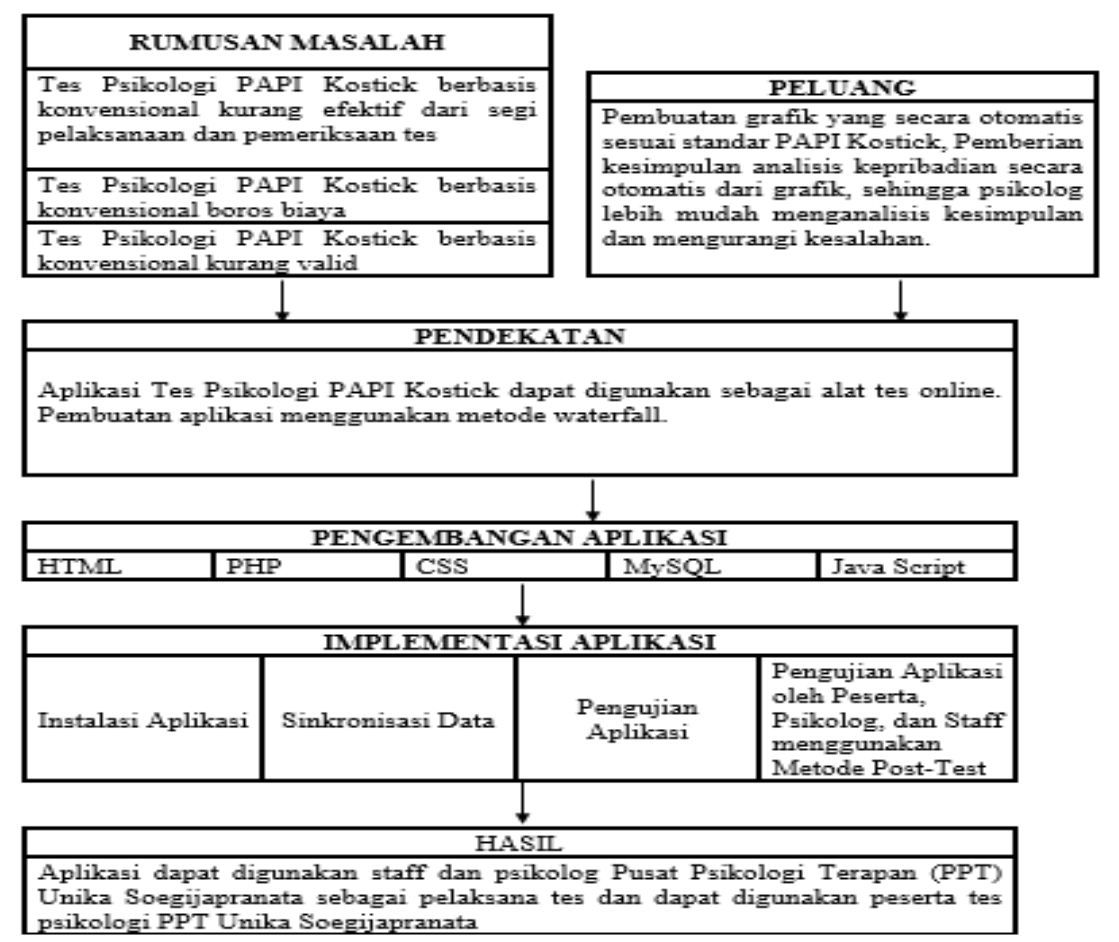

Figure 3.2 Mind Framework

\section{RESULTS AND DISCUSSION}

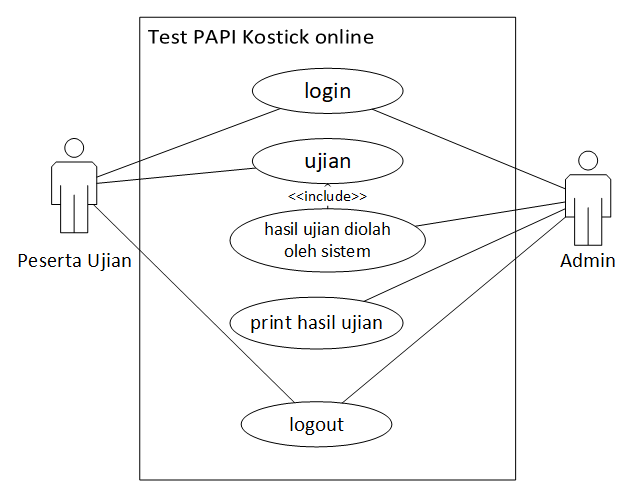

Figure 4.1 uses case
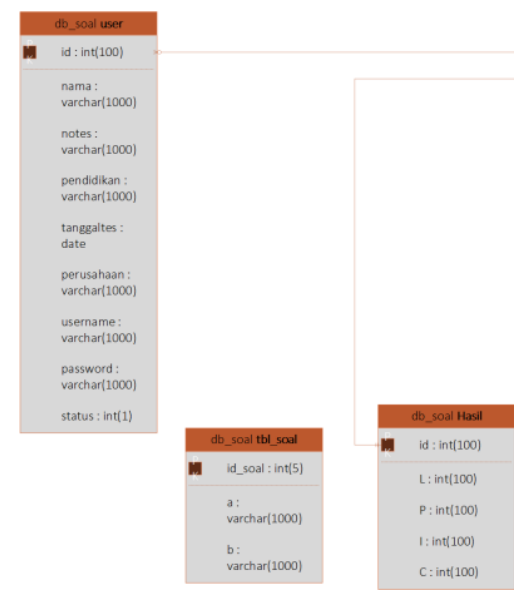

Figure 4.2 ERD
The stages of application design are, among others, the interview stage with the Head of UNIKA PPT Soegijapranata to obtain information related to the psychological test of PAPI Kostick, making ERDs, making mockups, and making uses cases. The Uses case is made in detail for the parts of each user and according to their duties. ERD is the database design of a system. In ERD a table relation is needed so that it can relate between one table and another. Mockups must be made as detailed as possible, because they are the reference in the design of a system to completion.

The process of making the PAPI Kostick psychological application as follows, the stage of making a login page, register, question sheet, admin, test results, and psychogram. With the existence of this system, when participants have filled out psycho-test answers, they will be automatically processed by the system into a number of certain letters that will be processed on the psychogram. The benefits generated are processing participants' answers faster and minimizing human error in the data processing. 


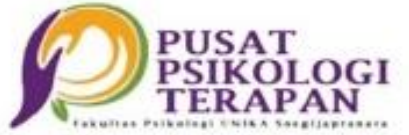

No Tas: C2

Nama mikael

Perusahanan : unika

Tanggal Tas : $2019-03-06$

PSIKOGRAM PAPIKOSTICK

\begin{tabular}{|c|c|c|c|c|c|c|c|c|c|c|c|c|c|}
\hline Dimensi & & Kebutuhan & 0 & 1 & 2 & $\mathbf{3}$ & 4 & $s$ & 6 & 7 & 8 & 9 & Keterangan \\
\hline \multirow{3}{*}{ KEPEMMMPINAN } & L & Peran-pemingin & & & & & & & & & & & \\
\hline & p & Menaendalkan $0 x y$ tain & & & & & & & & & & & \\
\hline & 1 & $\begin{array}{l}\text { Kemudahan membuat } \\
\text { kepulusan }\end{array}$ & & & & & & & & & & & \\
\hline
\end{tabular}

\begin{tabular}{|l|l|l|l|l|l|l|l|l|l|l|l|l|l|}
\hline Dimensi & & Kebutuhan & 0 & 1 & 2 & 3 & 4 & 5 & 6 & 7 & 8 & 9 & Keterangan \\
\hline \multirow{3}{*}{ GAYA KERJA } & C & Tipe Pengatur & & & & & & & \\
& D & Suka peketjase terperind & & & & & & & \\
\hline & R & Tipe teortis & & & & & & & & & & \\
\hline
\end{tabular}

\begin{tabular}{|c|c|c|c|c|c|c|c|c|c|c|c|c|c|}
\hline Dimensi & & Kebutuhan & 0 & 1 & 2 & 3 & 4 & 5 & 6 & 7 & 8 & 9 & Keterangan \\
\hline \multirow{3}{*}{ ARAH KERJA } & N & $\begin{array}{l}\text { Tpe Pernelesaian tugas secara } \\
\text { pribadi }\end{array}$ & & & & & & & & & & & \\
\hline & G & Perikragn sbg pekefia keras & & & & & & & & & & & \\
\hline & A & Haszat berprestasi & & & & & & & & & & & \\
\hline
\end{tabular}

Figure 4.3 Psychogram

From the results of a simple study that has been done has obtained some data as follows. Most participants who take the online psychology are 21 years old.

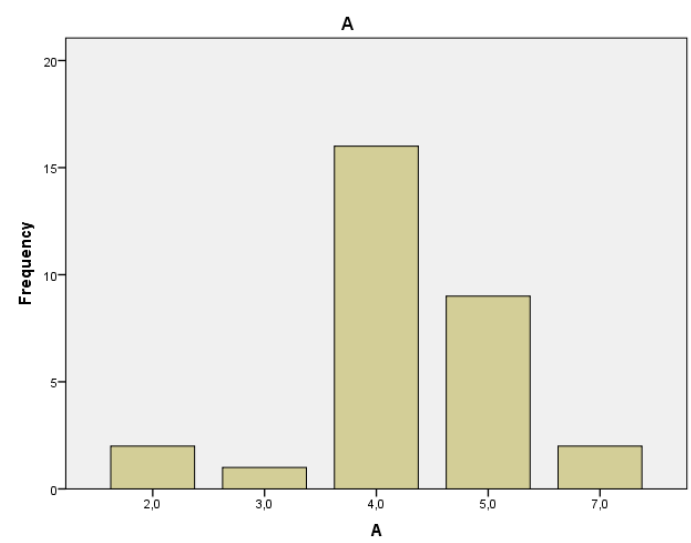

Figure 4.4 Age

Participants who participated in online psycho test for males amounted to 16 people while for women 14 people.

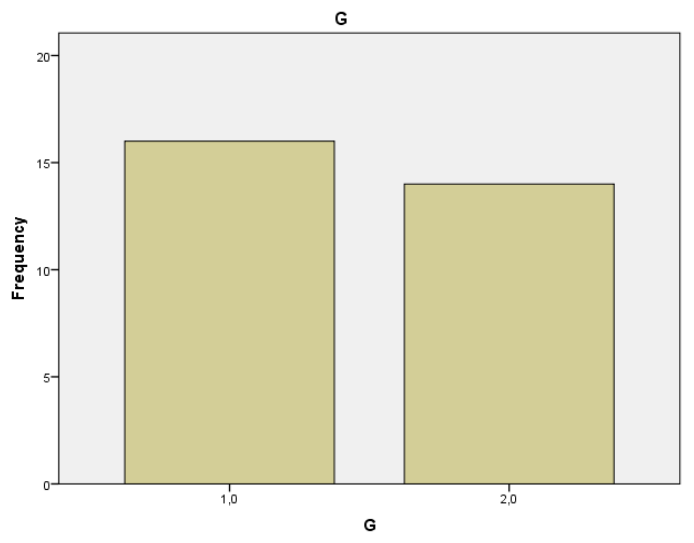

Figure 4.5 Gender

The following is an explanation of the correlation in table 4.3. The correlation between AQ and AU: shows that there is a relationship between gender $(\mathrm{G})$, the convenience of using the application (AQ), and the application appearance (AU). P AR correlation: shows that there is a strong relationship between ever using the psychological test application (P) and understanding the use of psychological test (AR) applications. AQ correlation G, AR, AS, AT, AU: shows that there is a relationship between the convenience of using a 
psychological test (AQ) and gender (G), but a strong relationship occurs between the convenience of using psychological test (AQ) and understanding of application (AR), satisfaction using the application psychological test (US), the use of long-term psychological application (AT), the display of online psychological test application (AU).

AR correlation P, AQ, AS, AT, AU: shows that there is a strong relationship between understanding using the application of the psychological test (AR) with the application of psychological test $(\mathrm{P})$, comfort using the psychological test application (AQ), satisfaction using the psychological test application (AS) , the use of psychological test applications for the long term (AT), application display (AU). US correlation AQ, AR, AT, AU: shows that there is a strong relationship between satisfaction using the application (AS) with comfort using the application psychological test (AQ), understanding using application psychological test (AR), use psychological test for long term (AT), display application (AU).

AT AQ, AR, US, AU correlation: shows that there is a strong relationship between the use of psychological test applications for long term (AT) with the convenience of using the psychological test application (AQ), understanding using the application of psychological test (AR), satisfaction using the psychological test application (AS) , application display (AU). AU correlation G, AQ, AR, AS, AT: shows that there is a relationship between the appearance of the psychological test application (AU) and gender (G). However, there is a strong relationship between application appearance (AU) and the convenience of using psychological test applications, understanding using the application of psychological test (AR), satisfaction using the psychological test application (AS), the use of psychological test applications for the long term (AT).

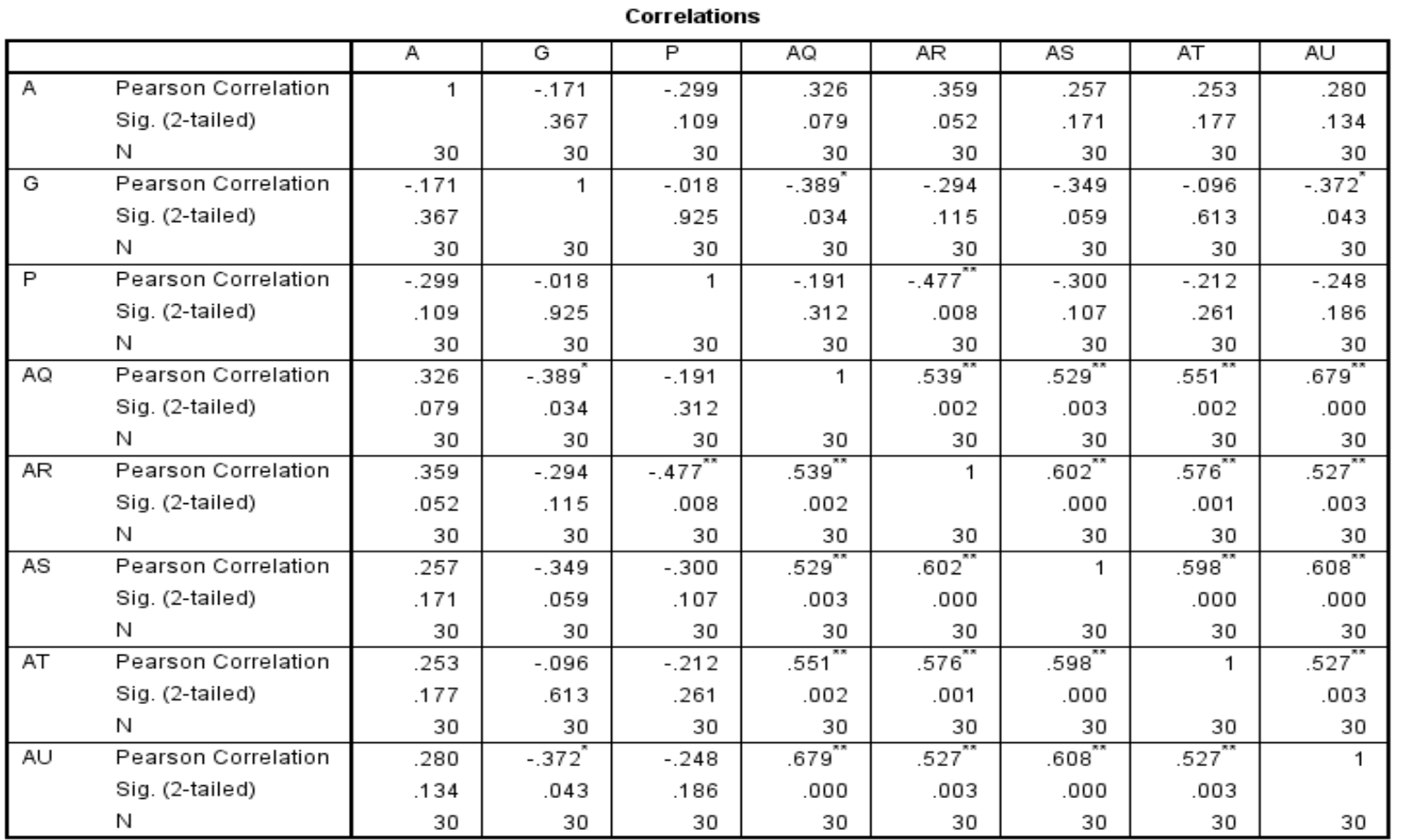

*. Correlation is significant at the 0.05 level (2-tailed).

**. Correlation is significant at the 0.01 level (2-tailed).

Figure 4.6 Correlation

\section{CONCLUSIONS}


From the research that has been done, the following conclusions can be drawn:

1. The stages of application design are, among others, the interview stage with the Head of UNIKA PPT Soegijapranata to obtain information related to the psychological test of PAPI Kostick, making ERDs, making mockups, and making uses cases. The Uses case is made in detail for the parts of each user and according to their duties. ERD is the database design of a system. In ERD a table relation is needed so that it can relate between one table and another. Mockups must be made as detailed as possible, because they are the reference in the design of a system to completion.

2. The process of making the PAPI Kostick psychological application as follows, the stage of making a login page, register, question sheet, admin, test results, and psychogram. With the existence of this system, when participants have filled out psychotest answers, they will be automatically processed by the system into a number of certain letters that will be processed on the psychogram. The benefits generated are processing participants' answers faster and minimizing human error in the data processing.

3. Making an online psychology test application PAPI Kostick has a continuity between understanding the application of psychological tests, convenience / convenience of using applications, display of applications, and long-term use of online psychological test applications. An easy-to-understand display will increase the convenience / ease of use of the application which means participants easily understand how to use the application so that the impact of the participants will be to use the psychological test application in the future.

\section{REFERENCES}

[1] A. Firdaus, "Web Thesis Psychology Simulator Application Thesis Case Study of the Psychology Institute of Bina Darma." 2013.

[2] F. Hesty et al., "Designing intelligent system applications for leadership evaluation based on Papi Kostick test," pp. 122-129, 2010.

[3] S. T. Informatika, K. I. Malang, T. Information, P. Tinggi, P. Science and Technology, and T. Information, "Journal of Information and Technology."

[4] S. E. Wijaya, "Psychological Expert System Design for Selection of Employee Acceptance at STMIK TIME Medan," vol. VI, no. 2, pp. 69-78, 2017.

[5] D. H. Putra, D. Puspitasari, and F. Rahutomo, "Development of Determination of Work Unit Systems at Pt. Various Indonesian Fashion Based on Psychotest."

[6] D. P. Cemani, A. A. Soebroto, and S. A. Wicaksono, "For Selection and Placement of Workers."

[7] A. S. M. B. S. I. Jakarta, "Web-Based Personality Tests for Determining Types," vol. XVII, no. 2, pp. 86-95, 2015.

[8] A. Lena and K. Ratna, "Understanding PHP and MySQL," Teknol Science. Inf., Pp. 2-3, 2008.

[9] A. Saputra, Building an Online Shop Application with PHP and SQL, 1st ed. Jakarta: PT Elex Media Komputindo, 2013.

[10] D. E. Hendrianto, "Making a LibraryBased Information System for Websites in the First State Donorojo Middle School in Pacitan," vol. 3, no. 4, pp. 5764, 2014.

[11] S. Ramadhani, U. Anis, and S. T. Masruro, "Designing a Geographic Information System for Health Services in Lamongan District with PHP MySQL," J. Tek., Vol. 5, no. 2, pp. 479-484, 2013.

[12] A. Saputra, "Mysql Database Management on Ftp Sites," pp. 155-162 
[13] J. D. A. N. Jquery, "Web-based image processing applications using javascript and jquery," pp. 1-8, 1969.

[14] "Designing Radio Streaming and Podcasting Web Content Innovations on Pacitan Fm Puspa Radio," vol. 4, no. 4, pp. 47-55, 2012. 